\title{
The Signatures of Acid Concentration on the Optical Band Gap and Associated Band Tails of Chitosan from Shrimp for Application in Optoelectronic Devices
}

\author{
Edwin Atego, John 0. Agumba, Godfrey 0. Barasa* \\ Department of Physical Sciences, Jaramogi Oginga Odinga University of Science and Technology (JOOUST), Bondo, \\ Kenya \\ Email: ^gobarasa@jooust.ac.ke
}

How to cite this paper: Atego, E., Agumba, J.O. and Barasa, G.O. (2022) The Signatures of Acid Concentration on the Optical Band Gap and Associated Band Tails of Chitosan from Shrimp for Application in Optoelectronic Devices. Advances in Chemical Engineering and Science, 12, 1-12. https://doi.org/10.4236/aces.2022.121001

Received: October 22, 2021

Accepted: December 6, 2021

Published: December 9, 2021

Copyright $\odot 2022$ by author(s) and Scientific Research Publishing Inc. This work is licensed under the Creative Commons Attribution International License (CC BY 4.0).

http://creativecommons.org/licenses/by/4.0/

\begin{abstract}
Over the recent years, the global increase of electronic wastes from electrical and electronic devices (e-wastes) has been on an alarming trend in quantity and toxicity and e-wastes are non-biodegradable resulting in its cumulative increase over time. Changes in technology and unrestricted regional movement of electrical devices have facilitated the generation of more e-wastes leading to high levels of air, soil and water pollution. To address these challenges, biodegradable organic components such as chitosan have been used to replace their inorganic counterparts for optoelectronic device applications. However, in-depth knowledge on how such materials can be used to tune the optical properties of their hybrid semiconductors is unrivaled. Thus, systematic studies of the interplay between the preparation methods and optical band gap and Urbach energy of such organic components are vital. This study has thus been dedicated to map out the effect of acid concentrations during chitosan extraction on the corresponding optical band gap and Urbach energy with a view to improving its applications in optoelectronic devices. The, 1.0 to 2.5 molar hydrochloric acid $(\mathrm{HCl})$ was used for 12 hours at room temperature during demineralization and 2.0 molar sodium hydroxide $(\mathrm{NaOH})$ during deprotonation processes. The absorbance spectrum of the samples was collected by UV-Vis spectrophotometer and band gap energies were analyzed by performing Tauc's plot. This study revealed that the energy band gap of chitosan extracted from $1 \mathrm{M} \mathrm{HCl}, 1.5 \mathrm{M} \mathrm{HCl}, 2.0 \mathrm{M} \mathrm{HCl}$ and $2.5 \mathrm{M} \mathrm{HCl}$ were $3.72 \mathrm{eV}, 3.50 \mathrm{eV}, 3.45 \mathrm{eV}$ and $3.36 \mathrm{eV}$ respectively. Furthermore, the Urbach energy of chitosan extracted from $1 \mathrm{M} \mathrm{HCl}, 1.5 \mathrm{M} \mathrm{HCl}, 2.0 \mathrm{M} \mathrm{HCl}$ and $2.5 \mathrm{M}$ $\mathrm{HCl}$ were $0.60496 \mathrm{eV}, 0.5292 \mathrm{eV}, 4724 \mathrm{eV}$ and $0.2257 \mathrm{eV}$, respectively.
\end{abstract}




\section{Keywords}

Chitosa, Optical Band Gap, Urbach Energy, Absorbance Spectrum, Tauc Plot

\section{Introduction}

The current global availability of millions of electrical and electronic devices has led to a new environmental pollution of electrical and electronic equipment or devices which are beyond their lifespan (e-wastes) [1]. Examples include computers, cellular phones, radio sets, and video cassettes among others [2]. These devices contain toxic inorganic components such as lead, arsenic, cadmium and cobalt amongst others, which poses adverse impact to animals, human beings and environment [3]. According to USA environmental protection agency (2004), only $4 \%$ of E-wastes are properly handled either by proper storage in warehouses, recycling or incineration which is hardly effective in solving related environmental concerns [4]. The in-cooperation of biodegradable polymers such as chitosan in the development of electronic devices by replacing their inorganic toxic counterparts has gained remarkable progress over the past years [5] [6]. However, chitosan based hybrid materials are still not effective in performance and stability, hence derailing the possibility of large scale production due to limited in-depth knowledge available on the opto-electronic properties of chitosan.

Chitosan is one of the most promising natural polymer on earth used in a wide range of applications with excellent film forming abilities, non-toxic, high mechanical strength, metal ion adsorption, and susceptible to chemical modification due to the presence of the reactive hydroxyl and amino functional group. Chitosan is a large structural homo-polysaccharide made up of N-acetyl-D-glucose amine molecules linked with beta $(1-4)$ bonds [7]. It is found on exoskeleton of crustaceans, insect and cell walls of fungi. The polymer exhibits widely differing physiochemical properties depending on sources and conditions for production. The extraction of chitosan from shrimp involves four major steps: demineralization (removing of calcium carbonate and calcium phosphate), de-protonation, de-coloration and de-acetylation. Chitosan has been extensively used to fabricate a variety of chitosan/metal oxide composites such as Chitosan/Zinc Oxide, Chitosan/Tin Oxide and Chitosan/Graphene oxide. This has been done with the view to replace the inorganic semiconductors used in fabricating electronic devices to aid in controlling e-waste pollution. However applications of chitosan in more advanced electronic devices which have high voltage operation, high temperature tolerance and high switching frequencies have not yet reached the expected standards [8]. This could be attributed to the fact that the optoelectronic properties of chitosan have not been extensively exploited. This could be a result of expensive and time consuming chitosan extraction methods.

The optical absorbance and band gap energy plots of semiconductors and that 
of chitosan can effectively be figured out by the analysis of the optical band gaps [9]. The band gap is the energy difference between the valence and the conduction bands. The appearance of optical band-gap in thin films is greatly affected by its microstructural constituents like short-range co-ordination, nano and $\mathrm{mi}$ cro crystallites, defects etc. Optically induced electronic transitions in devices can be achieved by determination of the optical absorption coefficient $(\alpha)$ near the fundamental edge. The optical absorption coefficient $\alpha$, is related to the samples thickness $(d)$ by the equation

$$
\alpha=\frac{2.303}{d} \times \text { absorbance }
$$

The absorption coefficient $(\alpha)$ can be used to calculate the optical energy band gap; $E_{g}$ by performing Tauc's plot [10] related by the equation

$$
\alpha h v=B\left(h v-E_{g}\right)^{r}
$$

Here $B$ is constant that is dependent on the transition probability and $r$ depends on the type of electronic transition. $r$ takes values of $\frac{1}{2}$ for direct allowed or 2 for indirect allowed transitions [11]. Plots of $(\alpha h v)^{1 / r}$ against $(h v)$ with different values of $r$ that gives a straight line will determine the type of transition. In this experiment, the value of $r$ was found to be $\frac{1}{2}$ for chitosan (chitosan has direct allowed band gap) since that value of $r$ gives the best linear graph of $(\alpha h v)^{2}$ against $(h v)$. The intersection of the straight line with the $h v$-axis was used to determine the optical gap energy $E_{g}$.

The photon energy is quantized through plank's law:

$$
\text { Energy, } h v=\frac{h c}{\lambda}=\frac{1240}{\lambda}
$$

From Equation (3), $h$ is planks constant; $c$ is the speed of light and $\lambda$ is the wavelength. Chitosan samples have shown high absorption of UV light about $90 \%-99 \%$ between $200-400 \mathrm{~nm}$ with very little transmission in the absence of reflection. From previous work darkness has also been recorded between $600 \mathrm{~nm}$ to $800 \mathrm{~nm}$ [12] [13].

The localized defect states in an optical band gap region of chitosan have been represented by the Urbach energy $E_{u}$ which is responsible for the formation of absorption tail in the absorption spectra [14]. It also indicates the disorder of phonon states on a chitosan film. The $E_{u}$ can be calculated from the absorption spectrum using the relation;

$$
\ln \alpha=\ln \alpha_{O}+\frac{h v}{E_{u}}
$$

where $\alpha$ is the absorption coefficient $\alpha=\frac{2.303}{d} \times$ absorbance .

The incident photon energy

$$
h v=\frac{h c}{\lambda}=\frac{1240}{\lambda}
$$


The $E_{u}$ is estimated from $\ln \alpha$ versus $h v$ plot from which the reciprocal of the slope obtained by fitting the linear part of the curve gives the value of $E_{u}$ [15] [16].

$$
E_{u}=\frac{1}{\text { slope }}
$$

Previous studies have revealed that the Urbach energy $\left(E_{u}\right)$ of chitosan has shown a remarkable increase from $1.11 \mathrm{eV}$ to about $2.22 \mathrm{eV}$ with increasing acid concentrations and this determines the electronic disorder which further affects the degree of disorder in the chitosan sample. These values are however expected to vary depending on the various extraction conditions of chitosan [12] [13].

In the present study, an in-depth analysis of the microstructure of chitosan solution prepared using different acid concentrations has been investigated using spectrophotometer. The underlying dependence of microstructure on the acid concentrations and the evolution of $E_{g}$ are addressed by assessing Urbach energy tail $\left(E_{u}\right)$ and associated weak absorption tail energy $\left(E_{t}\right)$. This was achieved by extracting chitosan from shrimp by chemical method using $1 \mathrm{M}$ $\mathrm{HCl}, 1.5 \mathrm{M} \mathrm{HCl}, 2 \mathrm{M} \mathrm{HCl}$ and $2.5 \mathrm{M} \mathrm{HCl}$ for 12 hours during demineralization and optical band gap and Urbach energy determined. The quantitative measurement of these optical parameters may help in tailoring and modeling the properties of chitosan composites for use in optical and optoelectronic components and devices.

\section{Experimental}

\subsection{Materials and Equipment}

Chitosan was chemically extracted from shrimp obtained from the shores of Lake Victoria in Kenya. Hydrochloric acid; acetic acid, sodium hydroxide, and deionized water (DI), were purchased from school lab agencies Kisumu (Kenya). All chemicals were of laboratory grade and used without further purification.

\subsection{Preparation of Chitosan}

To extract chitosan, four major steps were followed: pre-treatment, demineralization, de-protonation and de-acetylation:

Step 1: Pretreatment stage

This was carried out by washing the collected shrimps to remove the external matter and sun dried for four days. $100 \mathrm{~g}$ of the dry shrimp was soaked in $50 \mathrm{ml}$ of $2.5 \mathrm{M} \mathrm{NaOH}$ to dissolve the non-chitin organic matter.

Step 2: De-protonation stage

This pretreated shrimp shell was washed and dried for two days then grounded into fine powder (approximately $1.5 \mathrm{~mm}$ diameter). The chitosan powder was divided into four beakers each of 10 grams. Each of the samples was soaked into $1.5 \mathrm{M} \mathrm{NaOH}$ for 24 hours at room temperature to remove the proteins.

Step 3: Demineralization 
This process was achieved by soaking them in $1 \mathrm{M}, 1.5 \mathrm{M}, 2 \mathrm{M}$ and $2.5 \mathrm{M}$ molar hydrochloric acid respectively to eliminate the minerals for another 12 hours. The obtained chitin was washed then filtered to obtain chitin powder and heated in an oven at $60^{\circ} \mathrm{C}$ for $5 \mathrm{hrs}$.

Step 4: De-acetylation

De-acetylation (conversion of chitin to chitosan) was achieved by boiling each of the samples in $1.25 \mathrm{M} \mathrm{NaOH}$ at $100^{\circ} \mathrm{C}$ for six hours. The powder was then washed severally in distilled water. A white solid chitosan was obtained. The extracted chitosan was dissolved in $1 \mathrm{M}$ acetic acid and left to shake for 5 hours [17] [18] [19].

\subsection{Characterization}

Absorption spectra were recorded on Perkin Elmer Lambda 3 B UV-V is spectrometer of wavelength range between $200-800 \mathrm{~nm}$ at $0.1 \mathrm{~nm}$ interval. The optical band gap and Urbach energy were analyzed using origin software by performing Tauc plots.

\section{Results and Discussion}

\subsection{Effect of Acid Concentration on Absorbance Spectrum of Chitosan}

Absorbance spectra as functions of wavelength, for chitosan prepared by hydrochloric acid of varied concentrations were recorded within wavelength range of $200 \mathrm{~nm}$ to $900 \mathrm{~nm}$ and the results displayed as shown in Figures 1(a)-(d). The black color shows the experimentally measured data of absorbance spectrum while the red color shows the Gaussian fits of the curves.

From the graphs, the maximum absorbance peaks for chitosan extracted by 1 $\mathrm{M} \mathrm{HCl}$ was at $279.6674 \mathrm{~nm}, 1.5 \mathrm{M} \mathrm{HCl}$ was at $281.3584 \mathrm{~nm}, 2.0 \mathrm{M} \mathrm{HCl}$ at $282.5032 \mathrm{~nm}$ and $2.5 \mathrm{M} \mathrm{HCl}$ at $283.598 \mathrm{~nm}$ respectively showing steady increase with concentration as shown in the inset of Figure 2. The variation in wavelength can be attributed to the asymmetric stretching of $\mathrm{CH}_{3}$ and $\mathrm{CH}_{2}$ chitosan polymer [20].

FWHM was $42.41 \mathrm{~nm}$ for $1.0 \mathrm{M} \mathrm{HCl}, 41.02 \mathrm{~nm}$ for $1.5 \mathrm{M} \mathrm{HCl}, 38.90 \mathrm{~nm}$ for 2.0 $\mathrm{M} \mathrm{HCl}$ and $36.85 \mathrm{~nm}$ for $2.5 \mathrm{M} \mathrm{HCl}$ showing systematic decrease respectively. The wider peaks could be as a result of the stretching vibrations of hydroxyl, amino and amide groups [20]. From this analysis, it is noted that, all the samples have strong absorbance for ultraviolet light within the wavelength range $279 \mathrm{~nm}$ to $283 \mathrm{~nm}$. The variation in absorbance wavelengths can be ascribed to the elimination of minerals and the acetyl groups as more concentrated acids easily reduces calcium carbonate to water and carbon dioxide gas; while sodium hydroxide eliminates the protein. A red shift ( $\lambda_{\max }=279.67 \mathrm{~nm}$ to

$\lambda_{\text {max }}=283.60 \mathrm{~nm}$ ) was observed in the spectra of chitosan extracted by different concentrations of hydrochloric acid which can be attributed to the removal of impurities. This is in consistence with absorption spectrum reported in literature 


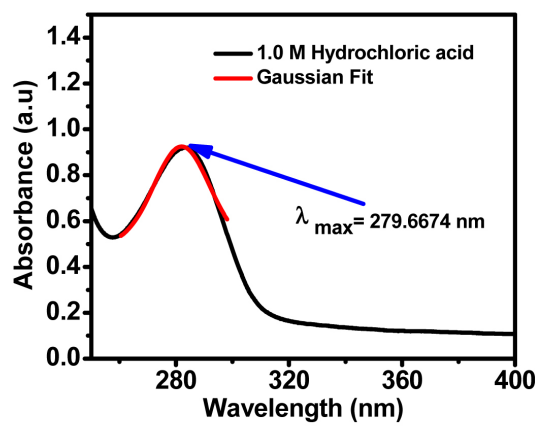

(a)

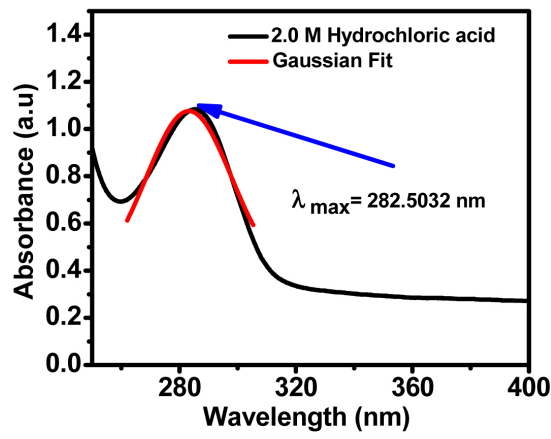

(c)

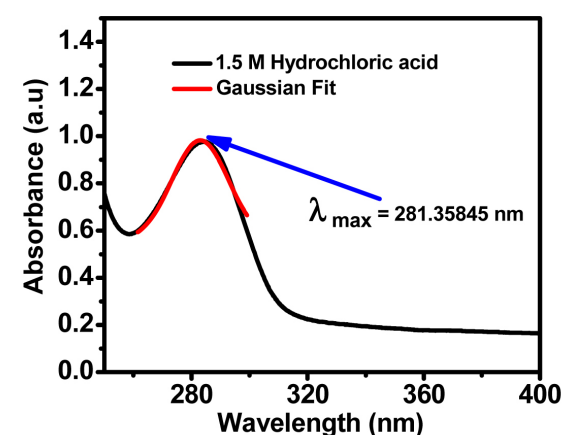

(b)

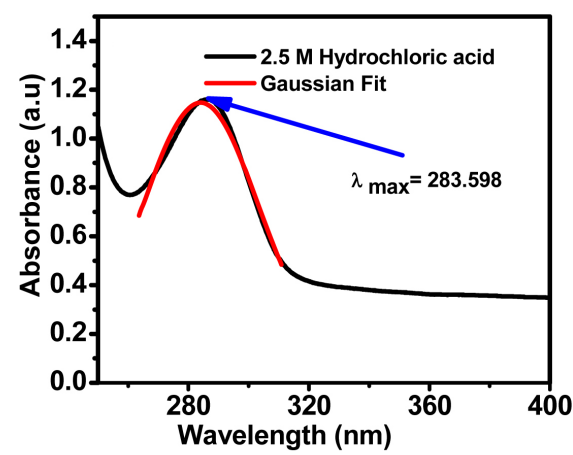

(d)

Figure 1. Absorbance spectra for chitosan prepared by a) $1 \mathrm{M}$, b) $1.5 \mathrm{M}$, c) $2 \mathrm{M}$ and d) 2.5 M hydrochloric acid.

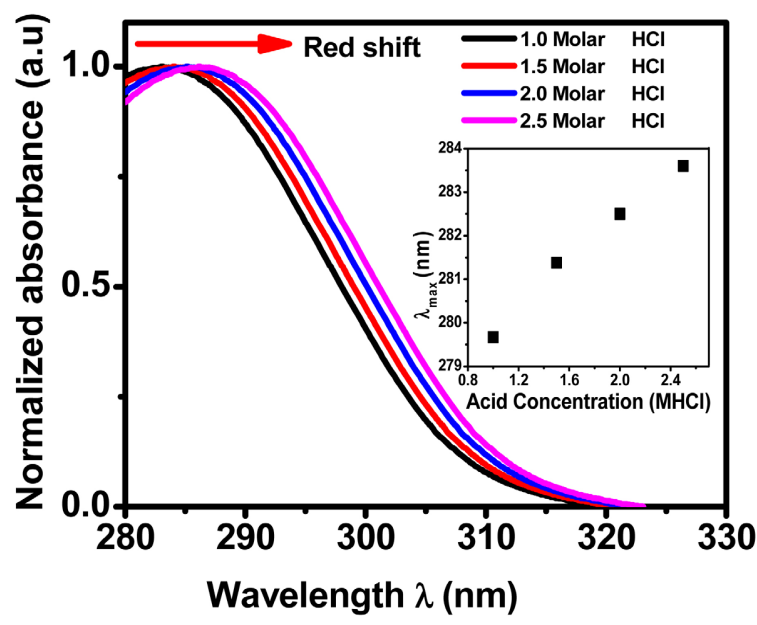

Figure 2. Plots of normalized absorption spectra as a function of wavelength for chitosan prepared by $1 \mathrm{M}, 1.5 \mathrm{M}, 2 \mathrm{M}$ and $2.5 \mathrm{M} \mathrm{HCl}$ showing red-shift of the absorption peak maxima.

[8] [13]. The variation in wavelength can be attributed to the asymmetric stretching of $\mathrm{CH}_{3}$ and $\mathrm{CH}_{2}$ chitosan polymer [20].

\subsection{Effect of Acid Concentration on Energy Band Gap $\left(E_{g}\right)$ of Chitosan}

The optical band gap for various samples was obtained by performing Tauc's 
plot as shown in Figures 3(a)-(d).

The comparison of energy band gap of chitosan prepared by dilute and concentrated hydrochloric acid within wavelength a range of $200 \mathrm{~nm}$ to $800 \mathrm{~nm}$ are shown in Figure 3. The extrapolated linear part to the $\mathrm{x}$-axis gives the energy band gap of each sample. The energy band gap $E_{g}$ for chitosan extracted by $1 \mathrm{M}$ $\mathrm{HCl}$ is at $3.7567 \mathrm{eV}, 1.5 \mathrm{M} \mathrm{HCl}$ is at $3.6887 \mathrm{eV}, 2.0 \mathrm{M} \mathrm{HCl}$ at $3.5700 \mathrm{eV}$ and 2.5 $\mathrm{M} \mathrm{HCl}$ at $3.4964 \mathrm{eV}$. It is evident that the energy bang gap of chitosan reduces with increase in acid concentrations. This could be as a result of the elimination of proteins and impurities within the as prepared samples.

From Figure 4, the energy band gaps are seen to reduce form from $3.76 \mathrm{eV}$ to $3.50 \mathrm{eV}$ with subsequent increase in acid concentrations. This might be attributed to the orderliness in the chitosan structure created by higher acid concentrations which have the effective elimination of impurities.

\subsection{The Effect of Acid Concentration on Urbach Energy $E_{u}$ of Chitosan}

The important features of Figure 5 are classified into three types of absorptions [21] [22]. First is region I. This region is attributed to the small optical absorption $(\alpha)$ governed by the optical transitions from one tail state to another tail state. These are called weak absorption tails (WAT). These localized tail states in amorphous structures arise from defects generated disorder. Second is the region- $\mathrm{U}$ where $\alpha$ is controlled by the transitions from the localized tail states

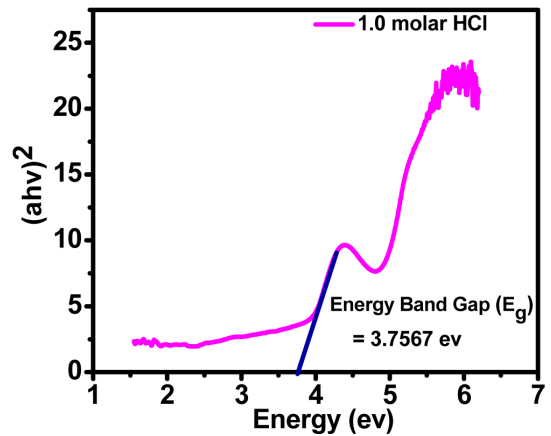

(a)

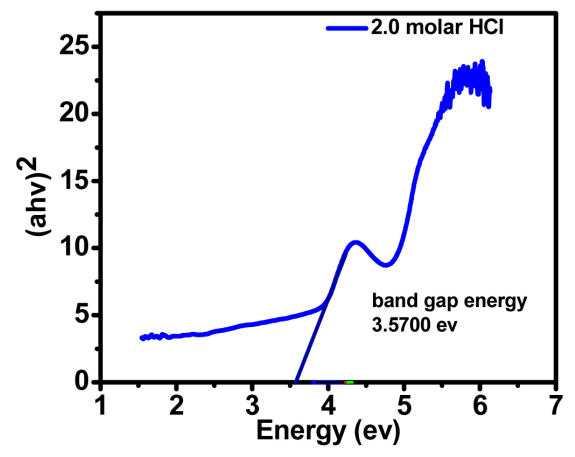

(c)

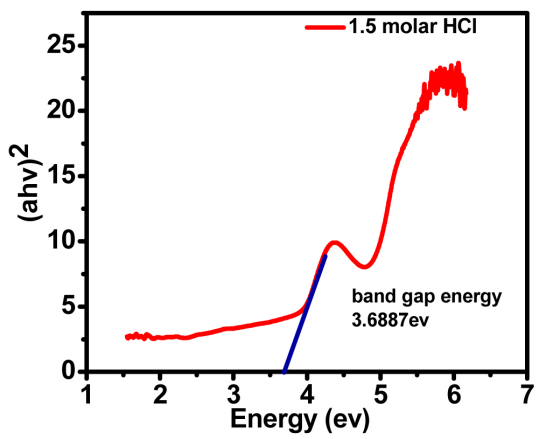

(b)

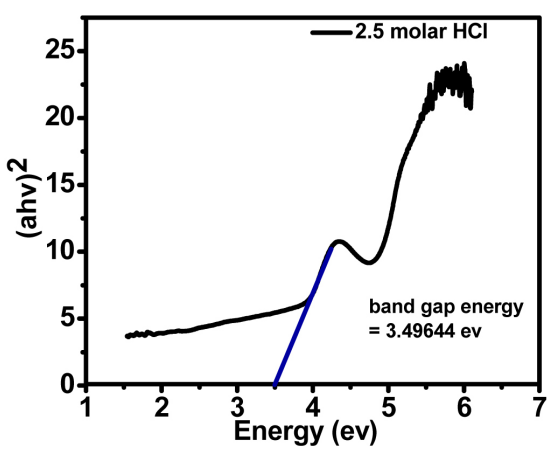

(d)

Figure 3. Plots of $(\alpha h v)^{2}$ as a function of energy $(h v)$ for chitosan prepared by $1 \mathrm{M}, 1.5 \mathrm{M}$, $2 \mathrm{M}$ and $2.5 \mathrm{M} \mathrm{HCl}$. 


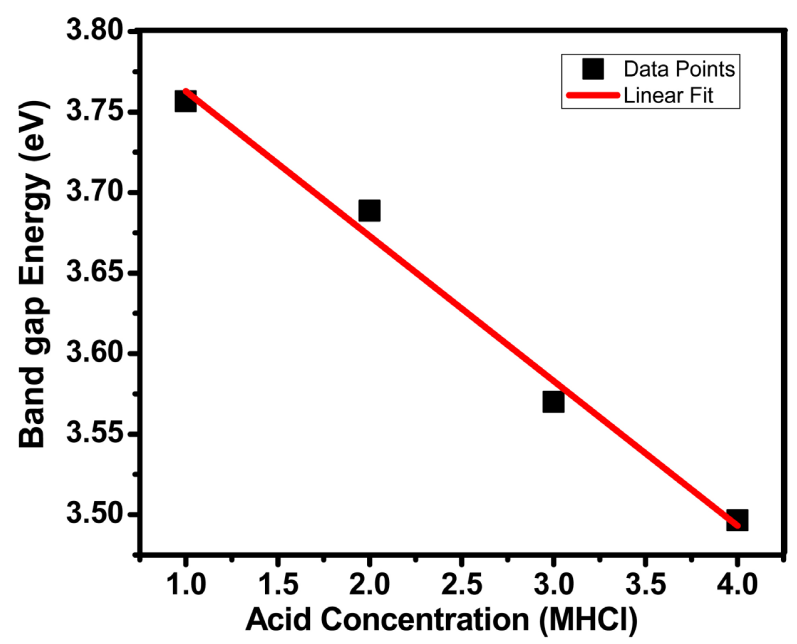

Figure 4. The energy band gaps as a function of acid concentration for chitosan prepared by $1 \mathrm{M}, 1.5 \mathrm{M}, 2 \mathrm{M}$ and $2.5 \mathrm{M}$ Hydrochloric acid.

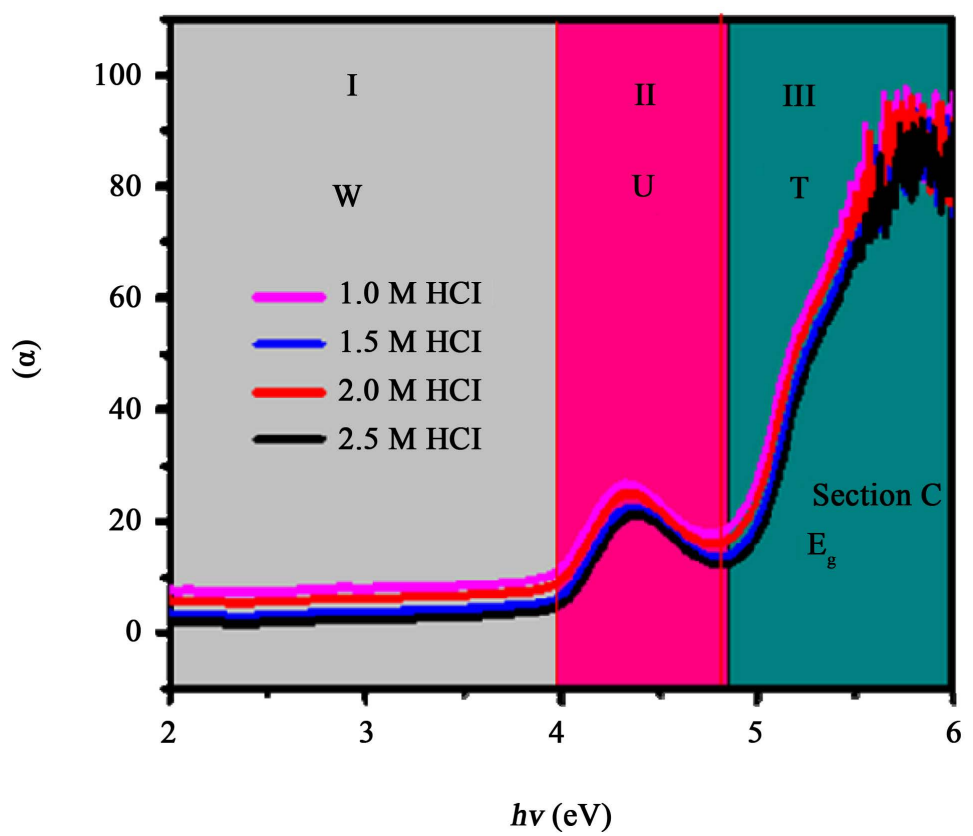

Figure 5. Plots of $\alpha$ as a function of $h v$ for chitosan prepared by $1 \mathrm{M}, 1.5 \mathrm{M}, 2 \mathrm{M}$ and 2.5 $\mathrm{M}$ hydrochloric acid showing three types of absorptions.

above the valence band to the extended states in the conduction band and/or from the extended states in the valence band to the localized states below the conduction band [21] [22]. In this region, the spectral dependence of $\alpha$ follows the Urbach rule. The third region $\mathrm{T}$ represents the range of $\alpha$ governed by the optical transitions from one extended state to another extended state.

The Urbach energy $\left(E_{u}\right)$ and the associated weak absorption tail energy $\left(E_{t}\right)$ for chitosan prepared by $1 \mathrm{M}, 1.5 \mathrm{M}, 2 \mathrm{M}$ and $2.5 \mathrm{M} \mathrm{HCl}$ within wavelength range of $200 \mathrm{~nm}$ to $800 \mathrm{~nm}$ were obtained by the gradients of the Urbach energy tail and the weak absorption tail energy and are shown in Figure 6. 


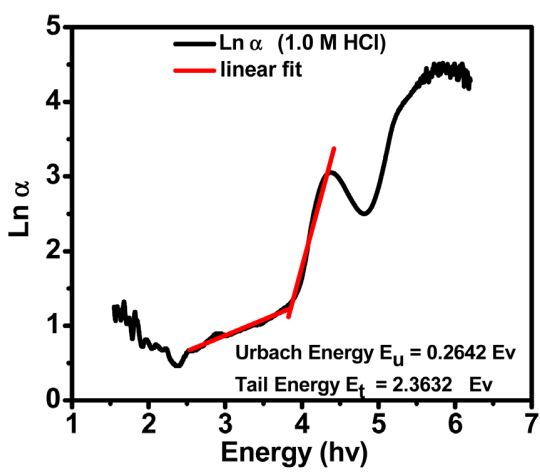

(a)

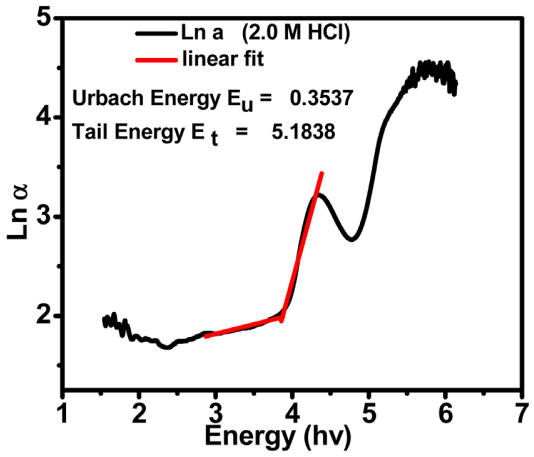

(c)

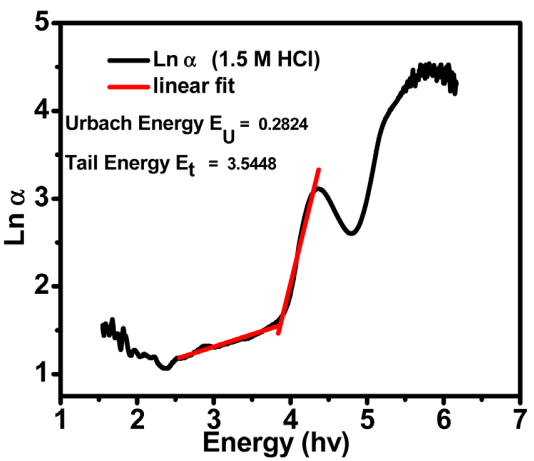

(b)

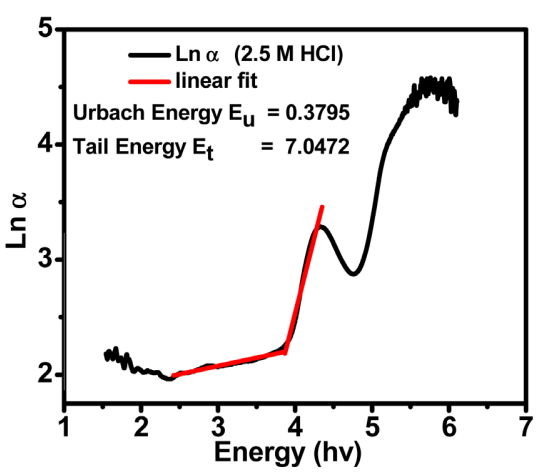

(d)

Figure 6. Plots of $\ln \alpha$ as a function of wavelength for chitosan prepared by (a) $1 \mathrm{M}$, (b) $1.5 \mathrm{M}$, (c) $2 \mathrm{M}$ and (d) $2.5 \mathrm{M}$ hydrochloric acid, respectively.

From the graph, chitosan prepared by $2.5 \mathrm{M} \mathrm{HCl}$ shows $E_{u}$ at $0.2257 \mathrm{eV}$ and $E_{t}$ at $7.0472 \mathrm{eV}$, for chitosan by $2.0 \mathrm{M} \mathrm{HCl}, E_{u}$ was at $0.47248 \mathrm{eV}$ and $E_{t}$ at 5.1838 $\mathrm{eV}$, for chitosan at $1.5 \mathrm{M} \mathrm{HCl}, E_{u}$ was $0.5292 \mathrm{eV}$ and $E_{t} 3.5448 \mathrm{eV}$ and for chitosan extracted by $1 \mathrm{M} \mathrm{HCl}, E_{u}$ was $0.60496 \mathrm{eV}$ and $E_{t} 2.3632 \mathrm{eV}$. The electronic disorder in the crystal (Urbarch energy) was found to be highest for chitosan extracted by dilute hydrochloric acid and lowest when a concentrated acid was used as shown in Table 1.

This difference could be due to the variations in the disorder or delocalized state of each sample. The defect in chitosan structures increases after de-protonation and demineralization leading to an increase in the electronic disorder for chitosan extracted by lower acid concentrations. The result shows that as the acid concentration increases, the chitosan solutions become more crystalline with increased band gap and reduced Urbach tail. It is noted from Table 1 that for specific acid concentrations, $E_{t}>E_{g}$. To obtain the resultant disorder in the chitosan sample $E_{u}$ and $E_{t}$ are can be added up. A plot of $E_{g}$ versus $\left(E_{t}+E_{u}\right)$ gives straight line graph as shown in Figure 7. After linear fitting, the intercept gives the maximum possible value of the energy band gap $E_{g}=3.897 \mathrm{eV}$, which is approximated to be the value of $E_{g}$ in the absence of disorders in the chitosan sample.

From Figure 7, energy band gap is much higher than the Urbach energy but the values reduce as the acid concentrations rises. 


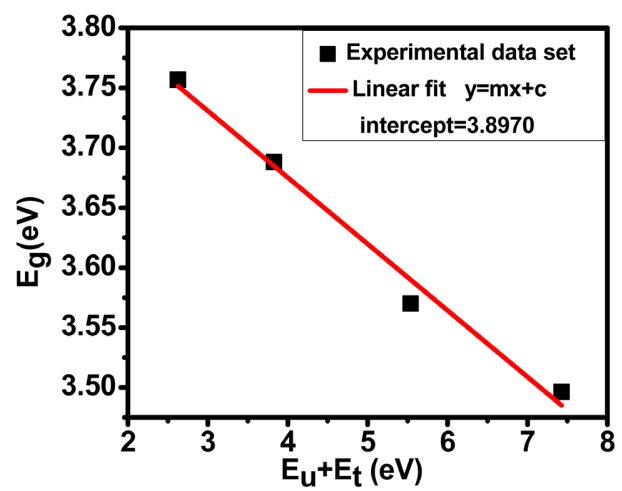

Figure 7. Plot of $E_{g}$ as a function of $\left(E_{t}+E_{u}\right)$ for chitosan prepared by $1 \mathrm{M}, 1.5 \mathrm{M}, 2 \mathrm{M}$ and $2.5 \mathrm{M}$ hydrochloric acid.

Table 1. Summary of optoelectronic properties of chitosan prepared by $1 \mathrm{M}, 1.5 \mathrm{M}, 2 \mathrm{M}$ and $2.5 \mathrm{M}$ hydrochloric acid.

\begin{tabular}{ccccc}
\hline $\begin{array}{c}\text { Hydrochloric } \\
\text { Acid } \\
\begin{array}{c}\text { concentration } \\
(\mathrm{M})\end{array}\end{array}$ & $\begin{array}{c}\text { Maximum } \\
\text { absorbance } \\
\text { Wavelength } \\
\lambda_{\max }(\mathrm{nm})\end{array}$ & $\begin{array}{c}\text { Optical } \\
\text { energy } \\
\text { band gap } \\
\left(E_{g}\right)\end{array}$ & $\begin{array}{c}\text { Eubach } \\
\text { energy } \\
\left(E_{u}\right)(\mathrm{eV})\end{array}$ & $\begin{array}{c}\text { Weak } \\
\text { absorption } \\
\text { tail } E_{t}(\mathrm{eV})\end{array}$ \\
\hline 1.0 & 279.667 & 3.7567 & 0.2642 & 2.3632 \\
1.5 & 281.3584 & 3.6887 & 0.2824 & 3.6448 \\
2.0 & 282.50 & 3.5700 & 0.3537 & 5.1838 \\
2.5 & 283.598 & 3.4964 & 0.3795 & 7.0472 \\
\hline
\end{tabular}

\section{Conclusion}

From the results of this study, the energy gap $E_{g}$ of chitosan extracted by $1,1.5,2$ and 2.5 molar $\mathrm{HCl}$ was found to be $3.7567 \mathrm{eV}, 3.67887 \mathrm{eV}, 3.5700 \mathrm{eV}$ and 3.4964 $\mathrm{eV}$ respectively. The Urbach energy $E_{u}$ was noted to increase from $0.2642 \mathrm{eV}$, $0.2824 \mathrm{eV}, 0.3537 \mathrm{eV}$ and $0.3795 \mathrm{eV}$ within the range of $1-2.5 \mathrm{Molar} \mathrm{HCl}$ concentration. From the analysis the weak absorption tails increased systematically from $2.3 \mathrm{eV}$ to $7.0 \mathrm{eV}$. It can be concluded that optical properties of chitosan are influenced by the acid concentrations used during demineralization. The maximum absorption peaks are observed to be shifted to longer wavelengths as the concentrations of the acid were raised. Consequently, the energy band gaps reduced with increase in acid concentration due to complete removal of impurities which implies lower excitation energy. The electronic disorder consequently decreases with increase in acid concentrations. These findings serve as a fundamental proof of concept that optical properties of chitosan can be tuned by varying the extraction parameters especially acid concentrations for potential applications in bio-semiconductors which can be of great impact on reducing e-waste pollution.

\section{Acknowledgements}

The authors would like to acknowledge the Physical Sciences department of 
JOOUST for availing equipment required for research. We also take this opportunity to thank all the colleagues in the department for support and encouragement during the entire period of this work.

\section{Conflicts of Interest}

Authors have no conflict of interest to declare.

\section{References}

[1] Agamuthu, P. and Victor, D. (2011) Policy Trends of Extended Producer Responsibility in Malaysia. Waste Management \& Research, 29, 945-953. https://doi.org/10.1177/0734242X11413332

[2] Mohan, D. (2008) Electronic Waste Management in Ghana. Department of Civil Engineering, Institute of Technology, p. 3, 40-60.

[3] Ladou, J. and Lovegrove, S. (2008) Export of Electronics Equipment Waste. International Journal of Occupational and Environmental Health, 14, 1-10. https://doi.org/10.1179/oeh.2008.14.1.1

[4] Chatterjee, S. and Kumar, K. (2009) Effective Electronic Waste Management and Recycling Process Involving Formal and Non-Formal Sectors. International Journal of Physical Sciences, 4, 893-905.

[5] Chandrakala, H.N., et al. (2014) Optical Properties and Structural Characteristics of Zinc Oxide Cerium Oxide Doped Polyvinyl Alcohol Films. Journal of Alloys and Compounds, 586, 333-342. https://doi.org/10.1016/j.jallcom.2013.09.194

[6] Tomar, A.K. (2011) Nano-Ag Doping Induced Changes in Optical and Electrical Physical Condensed Matter. p. 4066, 1919-1925.

[7] KIMS (2011) Chitin, Chitosan Oligosaccharides and Their Derivatives; Biological and Their Application. CRC Press, Boca Raton, 3-633.

[8] Solomon, L. (2019) Tuning the Band Gap of Reduced Graphene Oxide Using Chitosan for High Power and Frequency Devices. American Journal of Polymer Science, 7, 1-12.

[9] Thirunavukkarasu, N. (2005) Biology Nutritional Evaluation and Utilization of Mud Crab Scylla tranquebarica (Fabricius, 1798). Ph.D. Thesis, Annamalai University, Tamil Nadu.

[10] Aziz, S.B. (2017) Morphological and Optical Characteristics of Nano Composites. Nanomaterials, 7, 1-15. https://doi.org/10.3390/nano7120444

[11] Lian, K.Y., et al. (2013) Big Band Gap in Highly Reduced Graphene Oxide. The Journal of Physical Chemistry, 117, 6049-6054. https://doi.org/10.1021/jp3118067

[12] Neville, F. (2012) Electronic Processes in Non Crystalline Materials. Oxford University Press, Oxford.

[13] Eddya, M., Tbib, B. and EL-Hami, K. (2020) A Comparison of Chitosan Properties after Extraction from Shrimp Shells by Diluted and Concentrated Acids. Heliyon, 6, E03486. https://doi.org/10.1016/j.heliyon.2020.e03486

[14] Mohhamad, F.F., et al. (2015) Effect of Dopant Salt on Optical Parameters of PVA. Journal of Material Science, 26, 521-529. https://doi.org/10.1007/s10854-014-2430-0

[15] Rorza, J., et al. (2012) Cu Nanoparticles Induced Structural, Optical and Electrical Modification in PVA. Materials Chemistry and Physics, 134, 1121-1126. https://doi.org/10.1016/j.matchemphys.2012.04.004 
[16] Abdelaziz, M. (2011) Cerium (III) Doping Effects on Optical and Thermal Properties of PVA Films. Physica B: Condensed Matter, 406, 1300-1307.

https://doi.org/10.1016/j.physb.2011.01.021

[17] Alabaraoye, E., Achilonu, M. and Hester, R. (2018) Biopolymer Chitin from Various Marine Sea Shell Wastes: Isolation and Characterization. Journal of Polymers and the Environment, 26, 2207-2218. https://doi.org/10.1007/s10924-017-1118-y

[18] Kaya, M., et al. (2014) Extraction and Characterization of Chitin and Chitosan from Six Different Aquatic Invertebrates. Food Biophysics, 9, 145-157. https://doi.org/10.1007/s11483-013-9327-y

[19] Islam, A., et al. (2020) Extraction and Worth Evaluation of Chitosan from Shrimp and Pawn Co-Products. American Journal of Food Technology, 15, 43-48. https://doi.org/10.3923/ajft.2020.43.48

[20] Guo, M., et al. (2005) Hydrothermal Growth of Well Aligned ZnO Nano Rod Arrays. Journal of Solid State Chemistry, 178, 1864-1873. https://doi.org/10.1016/j.jssc.2005.03.031

[21] Singh, J. (2006) Optical Properties of Condensed Matter and Applications. John Wiley and Sons Ltd., Hoboken. https://doi.org/10.1002/0470021942

[22] Adachi, S. (1999) Optical Properties of Crystalline and Amorphous Semiconductors: Materials and Fundamental Principles. Springer Science + Business Media, LLC, Berlin. 